\title{
ACULTURACIÓN DE IDA Y VUELTA: MISIÓN Y EDUCACIÓN JESUITA \\ EN AMÉRICA Y ASIA
}

\author{
ESTHER JIMÉNEZ PABLO ${ }^{1}$
}

\begin{abstract}
RESUMEN: En este artículo homenaje al P. Manuel Revuelta se aborda el estudio de las misiones jesuitas teniendo en cuenta la adaptación de sus estrategias a las gentes y culturas a evangelizar. Desde una perspectiva comparativa entre América y Asia se analiza la aculturación de los nativos, pero también la de los misioneros, y su capacidad de integración de "unos» en la cultura de los "otros». Asimismo, la expansión de la evangelización y el éxito de la educación jesuita en estos continentes dependió también de otros factores determinantes como el contexto político en el que se originaron las misiones, y el grado de implicación de los nativos en el progreso de la misión.
\end{abstract}

PalABRAS CLAVE: Misiones jesuitas; aculturación; educación; Asia y América.

\section{Two-way cultural transmission: Mission and Jesuit education in America and Asia}

ABSTRACT: The aim of this tribute to Manuel Revuelta S.I. is the study of Jesuit missions taking into account the adaptation of their strategies to the groups of people and cultures to be evangelized. The acculturation of the natives is analyzed from a comparative perspective between America and Asia, but also the acculturation of the own missionaries, and their capacity to integrate themselves into the culture of the "others". Likewise, the expansion of evangelization and the success of Jesuit education in these continents also depended on other determining factors such as the political context in which the missions originated, and the involvement of the natives in the progress of the mission.

KEY WORDS: Jesuit missions; acculturation; education; Asia and America.

\footnotetext{
1 Profesora en la Unidad Docente de Didáctica de las Ciencias Sociales, Universidad Complutense de Madrid. Correo electrónico: ejimenezpablo@ucm.es.
} 


\section{INTRODUCCIÓN}

Elegir un tema de investigación del legado del P. Revuelta no es tarea fácil, y más si se tiene en cuenta su capacidad para abordar casi todas las cuestiones de la historia de la Compañía de Jesús. Escribió más de ciento cincuenta artículos y capítulos de libro, analizando, siempre con rigor y en profundidad, cuestiones políticas, educativas, misionales, espirituales, etc. Y aunque experto en la Historia de la Compañía restaurada, no dejó de enseñarnos sobre la Compañía de Jesús desde sus orígenes. Su dominio de esta Historia tampoco conocía fronteras, llegando a interesarse por la labor de los jesuitas en otros continentes como en América y en Asia. Y es precisamente en estos amplios espacios donde voy a centrar este estudio homenaje.

El P. Revuelta trabajó sobre Oriente en artículos como Los ritos chinos y los jesuitas en el siglo XVIII, según la documentación franciscana en el volumen 54/104 del año 1996 de Miscelánea Comillas (pp. 143-173), donde analizó las dificultades que encontraron los misioneros jesuitas en China, ya fuera por las controversias entre distintas órdenes religiosas por los ritos chinos, por las condenas pontificias, y como ocurría a menudo en imperios asiáticos, por las persecuciones llevadas a cabo por parte de las autoridades locales. De esta misma revista, y dirigiendo la mirada a la educación y misión en el Nuevo Continente, al que dedica más estudios que a Oriente, publicó en el volumen 46/88-89 del año 1988 el artículo Las misiones de los jesuitas españoles en América y Filipinas durante el siglo XIX (pp. 339-390), donde estudió los orígenes de la nueva Compañía en las provincias de ultramar, repasando la expulsión y la compleja vuelta de la Compañía a una organización en los países de dominio español, pero también en los ya emancipados. Nos ofrecía las claves de las misiones del siglo XIX, cuando se dio esa «segunda expansión misional», que como él mismo señalaba, era obra casi exclusiva de las órdenes religiosas, y en ella los jesuitas volvieron a destacar.

Otro amplio campo de investigación del P. Revuelta fue la Educación jesuita. Su sentido crítico le llevó a publicar algunos trabajos, como señalamos, no sólo sobre educación en España sino también en América. En sus artículos dedicados al continente americano afirma que una historia de la educación en España si quiere ser completa, debe contar necesariamente con su prolongación en Ultramar. A la vez que reconoce que se debe respetar la diversidad y tratar de trabajar las peculiaridades de cada territorio o nación hispanoamericana. Entre sus estudios de la Compañía restaurada destacan La educación en América y Filipinas: enseñanza de los jesuitas en Hispanoamérica (1994, pp. 513-518) y Los colegios jesuitas en Hispanoamérica en el siglo XIX (1988, pp. 441-447). En éstos se muestra muy crítico con 
la labor pedagógica de la Compañía, ensalzando las luces, pero apreciando al mismo tiempo las sombras.

Mi interés por la labor educativa de los jesuitas en las misiones me lleva a destacar un artículo del P. Revuelta titulado Jesuitas en América: utopía y realidad en las reducciones del Paraguay (2007, pp. 31-47), en el que analiza las reducciones guaraníes y presenta lo que se pretendía y lo que se consiguió en ellas. Este artículo será la base de mi estudio y me permitirá realizar una comparativa, no sólo con otros estudios sobre el proceso evangelizador y el aprendizaje en las misiones americanas, sino también con las estrategias misionales y educativas utilizadas en las misiones orientales, haciendo especial referencia al caso japonés y chino. Intentando no incurrir en una generalización banal, trataré unos puntos muy concretos para poder perfilar un método jesuítico capaz de adaptarse a espacios tan distintos como Asia y América, teniendo como protagonistas a los jesuitas españoles y portugueses que soñaron con «cristianizar», y en ocasiones con «civilizar», a otros mundos.

\section{EL ORIGEN DE LAS MISIONES EN ASIA Y AMÉRICA EN SU CONTEXTO POLÍTICO}

El P. Revuelta siempre partía de premisas muy reflexivas, con una introducción que aportaba las claves de sus estudios. Cuando se trata de misiones, los artículos de nuestro jesuita suelen iniciarse con una contextualización política, consciente de la importancia de tener el favor de las autoridades del lugar que determinaba el éxito o el fracaso de la acción evangelizadora. Comenzaré, por tanto, por esta breve premisa desde Asia y América para poder entender el desarrollo de las estrategias metodológicas en las misiones jesuitas.

La expansión evangelizadora de los jesuitas empezó en Asia antes que en América. En 1542, apenas dos años más tarde de la fundación de la Orden, Francisco Javier llegaba a la ciudad de Goa en la India portuguesa. Mientras que la primera presencia jesuita en América se data en 1549, en Brasil, con la llegada del beato José de Anchieta. Para el caso de la América castellana, hubo que esperar al generalato de Francisco de Borja, concretamente al año 1566, para ver la llegada de los primeros jesuitas a la Florida. En Oriente, por tanto, los jesuitas fueron de las primeras órdenes en llegar, mientras que, en América, la Compañía fue de las últimas, pues las órdenes mendicantes llevaban de ventaja medio siglo de actividad misionera. De estos datos sorprende la tardanza en llegar jesuitas a la América española. No fue por no 
querer los dos Generales anteriores, ni por falta de peticiones de virreyes y gobernadores que solicitaban su presencia y predicación, sino por la oposición de los letrados castellanos en la corte madrileña al envío de jesuitas al territorio americano, pues no se fiaban de que implantasen el proceso de confesionalización de Felipe II en sus misiones. Esta situación cambió en el año 1564, cuando un miembro de la facción ebolista, don Juan Vázquez de Arce, nombrado presidente del Consejo de Indias, consiguió aprobar por primera vez para los jesuitas la ampliación de la evangelización en las Indias castellanas (Borja de Medina, 2000, p. 183). Todavía, las reticencias de los letrados castellanos desde el Consejo de Castilla, especialmente las del presidente e inquisidor general, don Diego de Espinosa, consiguieron retener a los jesuitas sin dejarles embarcar, hasta que el 3 de marzo de 1566, el propio Felipe II escribía al P. Araoz para encargarle que enviase 24 jesuitas a sus Indias para la conversión e instrucción de los naturales. Sobre este contexto político entre la facción castellana y la ebolista me remito a la amplia bibliografía del equipo de Martínez Millán (Martínez Millán y Fernández Conti, 2005). En este tardío triunfo, hay que destacar la acción del P. Francisco de Borja junto con el partido ebolista para conseguir abrir a la Compañía las puertas de los territorios americanos del monarca español. Es indudable que el generalato del P. Borja representa un momento de esplendor para la expansión misional de la Orden, siendo durante su mandato cuando se fundaron las provincias jesuíticas de Perú y de México en 1572 (Borja de Medina, 2000, p. 200).

El hecho de llegar antes al este que al oeste, se tradujo en una primera experiencia misionera en Oriente que se intentó trasladar a América, como reflejan las cartas de los Generales. Sin embargo, pronto muchos de los instrumentos metodológicos utilizados en Asia se juzgaron inapropiados para América, teniendo que diseñar nuevas estrategias para el Nuevo Continente. La diferencia del contexto de poder obligó a los jesuitas a variar de estrategia, porque la libertad que la Compañía sintió en América, respaldada por la conquista de las coronas ibéricas, no la sintieron en Oriente, donde los grandes imperios y reinos asiáticos les obligaron a actuar largas temporadas en la sombra y, en muchos casos, como es claramente el de Japón, a expensas de los intereses comerciales con Occidente.

Ahora bien, existió el interés por conquistar China y Japón, y ese sueño fue alimentado por algunos jesuitas como el P. Alonso Sánchez que vieron, en la teoría, la posibilidad de cristianizar estos imperios lejanos. Conquistar China significaba dominar el imperio más poderoso y vasto de Asia, lo que favorecería el sometimiento del resto de reinos y pueblos orientales que dependían de China (Peixoto de Araújo, 2000, p. 85). Este plan de conquistarla comenzó a tener eco desde la ocupación de Filipinas (Cervera Jiménez, 
2013), pero años más tarde, se planteaba como una posible realidad, cuando se incorporó Portugal y sus colonias a la Monarquía Hispana en 1580. Entonces, la sensación de hacer realizable la Monarquía Universalis de Felipe II se hacía más palpable. El P. Alonso Sánchez escribió un memorial con dieciséis capítulos enviados al Consejo de Indias justificando tanto legal era una guerra justa y lícita- como moralmente - la necesidad de extender el catolicismo- la ocupación de China. Señalaba, además, que era la única vía posible de conseguir la evangelización de todo Extremo Oriente, y se debía hacer rápido, pues no convenía dejar la oportunidad de expandirse a los musulmanes por estos imperios (López-Gay, 2000, pp. 107-108). Como se sabe, el P. José de Acosta fue quien refutó las teorías del P. Sánchez. Teorías que por otra parte fueron escuchadas por la facción castellana desde la corte madrileña, pues en la década de los 80 del siglo XVI estaba en sus manos el gobierno de la Monarquía Hispana, y uno de sus principales cometidos era apoyar la expansión militar de la Monarquía (Martínez Millán, 2003). Desde luego, la curia jesuítica en ese momento, siendo general el P. Claudio Aquaviva, en la misma línea de los generales que le precedieron, Ignacio, Laínez, Borja y Mercuriano, apoyaron al P. Acosta, pues se habían negado siempre a una conquista de China dada la sofisticada organización de este Imperio, su excesivo centralismo y jerarquización social, y el miedo a que, si quiera el intento, significara la expulsión de la Compañía de todo el continente asiático.

Era una realidad que Extremo Oriente se tornaba difícil de evangelizar por las órdenes religiosas, y que ganarse la confianza de las autoridades locales era todo un reto para los misioneros. En Japón, los bonzos budistas, que fueron quienes realmente influyeron en la religiosidad de las élites niponas, fomentaban el odio hacia los jesuitas y las persecuciones a los misioneros. Con las primeras persecuciones de 1587, la sombra del martirio ponía en riesgo la continuidad de los misioneros en las islas. De manera que en Japón se frustraron una y otra vez los planes de la Compañía de expansión del cristianismo. Al tener que pasar los jesuitas temporadas ocultos, algunos de ellos pensaron, no en solicitar la conquista de Japón, que por otra parte Francisco Javier ya había sido el primero en oponerse a cualquier tentativa de ocupación, sino en pedir crear una fortaleza como refugio de los misioneros y los bautizados. Cuando la Monarquía hispana y la portuguesa se unieron bajo la corona de Felipe II, el P. Luís Fróis, célebre misionero portugués, solicitaba a Roma lo siguiente:

Lo que mucho importa, y para conservarse la Compañía y la cristiandad en Japón no se excusa con necesidad absoluta, es haber en estas partes un fuerte o fortaleza en el cual se puedan recoger los Padres cuando suceda alguna persecución; donde además puedan guardar la hacienda, vestidos y el remedio para su 
sustentación, y que esté puesta en la mano del rey Felipe con 200 o 300 soldados con su guarnición. (Jap. Sin. 45, I, 132v, cita López-Gay, 2000, p. 110)

Del mismo parecer era el viceprovincial de la misión japonesa, Gaspar Coelho, también de origen portugués quien solicitó a la curia jesuítica que Felipe II por la fuerza construyera una fortaleza en Japón. Es decir, lo que solicitaban estos jesuitas era el respaldo militar de la Monarquía Hispana. No obstante, desde las altas esferas de la Compañía se prohibió tratar de este asunto; ni el general Aquaviva, ni tampoco el P. Alessandro Valignano, visitador de las Indias Orientales y máxima figura de las misiones en Japón, permitieron que tal propuesta llegara a Madrid (López-Gay, 2000, pp. 107-108). Cabe añadir que estos jesuitas actuaron buscando el respaldo de la corona al ver peligrar sus misiones. Además, valoraron que Japón, por sus reducidas dimensiones, era más fácil de cristianizar que China, y que era un momento propicio, dado que el territorio insular se encontraba, a finales del siglo XVI, muy descentralizado por las luchas internas de poder entre los daimyos.

\section{3. ¿ACULTURACIÓN DE LAS POBLACIONES O DE LOS MISIONEROS?}

Ciertamente, el P. Revuelta en su artículo de las reducciones del Paraguay señalaba que en América se trató de implantar un proceso de aculturación a los indígenas. Esto se traduce en algo más profundo que enseñar el evangelio o los ritos católicos, conlleva además la introducción de costumbres españolas (Revuelta, 2007, p. 34). En definitiva, de trasladar una cultura en otra. En Asia, centrándome en China o Japón, esto fue impensable, la aculturación llegó por parte de los misioneros a las costumbres orientales si querían tratar de introducir el evangelio. Lógicamente esta aculturación tiene mucho que ver con el punto anterior, dado que está supeditada al mayor o menor sometimiento de la población, o si hubo o no conquista, lo que sitúa al misionero en una posición de superioridad o sometimiento al componente local. No obstante, esto se debe matizar más para entender la complejidad del tema, porque presenta múltiples variables.

En América, tanto en las provincias jesuitas de Brasil como en las de Perú o México, se pueden fijar las siguientes etapas del proceso apostólico: tendríamos una primera fase de misioneros jesuitas que comienzan su actividad sin interferir ni en la organización social o económica de las comunidades indígenas, simplemente se trataba de acercar el catolicismo a estas comunidades de manera muy superficial, consiguiendo algunas conversiones. En segundo lugar, tendríamos otro momento más avanzado en tiempo en el que 
los jesuitas se introducen en los poblados, conviven con distintas comunidades tribales, forman parte de ellas, les enseñan el cristianismo e incorporan costumbres europeas especialmente en terreno agrícola, que mejoran la subsistencia. Y la última etapa que sería la creación de poblados indígenas en nuevos espacios, partiendo de cero, asegurando un terreno fértil y el aislamiento del contacto con los colonos, en el que los misioneros jesuitas conservan para sí tanto el poder espiritual como el temporal. Un tipo de estos poblados son, lógicamente, las reducciones jesuíticas (Couto, 2000, p. 65). Todo este proceso de actividad misionera que observamos en la América hispano-portuguesa se llevó a cabo a lo largo de décadas de actividad misionera; fue un proceso muy lento. Tenemos el resultado, que fueron las primeras reducciones guaraníes, a principios del siglo XVII, luego llegaron las de los indios pampas, mapuches, mojos o tiquitos. Pero que necesariamente tuvo que haber primero, décadas antes, un contacto previo con las comunidades indígenas, luego una convivencia y luego un traslado. No obstante, en los siglos XVI y XVII también se daba el caso de jesuitas que trataron de acercarse a grupos de indígenas más alejados de las ciudades coloniales, y adentrados en la profundidad de las selvas o en espacios de difícil acceso, que sufrieron martirio, sin poder llevar a cabo su misión.

Aparte estaba la vida en las ciudades, donde los jesuitas fundaron colegios, y era como señalaba el P. Revuelta un transvase del estilo de enseñanza español al americano (Revuelta, 2007, p. 35). Fuera de las ciudades era donde se daban las misiones con pueblos indígenas, a los que les inculcaban el evangelio, manteniendo gran parte de su identidad indígena en muchas de sus costumbres. Fue una aculturación de los nativos muy gradual. La parte simbólica y religiosa era la católica, pero en la práctica popular se mezclaba el catolicismo con otros ritos y creencias arraigadas que pervivieron en el tiempo. Sobrevivieron muchas prácticas locales porque no chocaban ni iban en contra de las creencias católicas. La práctica, por tanto, era la parte más laxa, y derivó en muchos casos en un sincretismo religioso con el catolicismo. Seguramente lo difícil no era que incorporaran la religión cristiana a sus creencias, sino que abandonaran aquellas costumbres no compatibles con el catolicismo como la antropofagia o la poligamia.

Si nos fijásemos en el origen de las misiones jesuitas en América, en las primeras etapas del proceso se usa el término metodológico de «misiones volantes o itinerantes». Como los poblados indígenas se hallaban repartidos, muchos de ellos alejados entre sí, y los misioneros de mediados y finales del siglo XVI no eran tan numerosos, se vieron obligados a realizar visitas itinerantes y temporales a los poblados de la mano de uno o dos padres jesuitas, acompañados de algún hermano coadjutor. Cuando se conseguía un número 
considerable de bautizados, tras convivir un tiempo con una comunidad indígena, se les construía una capilla para mantener vivos y presentes los ritos de la nueva religión, y los padres podían entonces visitar otros poblados. Una vez introducido el cristianismo, los padres jesuitas a veces podían llegar a visitar más de un centenar de poblados, durando cada visita entre dos y cinco días (Borja de Medina, 2000, p. 191).

La itinerancia acabó en algunos lugares cuando se crearon nuevas aldeas o poblados de indígenas dirigidos por jesuitas, siendo las más sofisticadas las reducciones jesuíticas. Estas últimas se interpretan como ciudades de indios libres, donde no se permitía el contacto con colonos, protegiendo así a las comunidades de la esclavitud de las encomiendas. En las reducciones se identifica claramente una estructura civil y jurídica, con un sistema de mantenimiento económico bien organizado (Revuelta, 2007, p. 47). En ellas se juntaban distintas comunidades indígenas, con creencias y costumbres diferentes. Se promulgaron normas tales como no tener más de una esposa, utilizar ropa en una línea más europea, aplicar la justicia regia, etc., acompañado de un reparto de tierras y del aprendizaje del cultivo de las mismas (Couto, 2000, pp. 76-77). El llegar a la creación de poblados de indígenas y de las reducciones significó una intensificación de la aculturación de los indígenas; no sólo se convirtieron en fieles cristianos, sino también en súbditos de las coronas ibéricas. Se contó con nuevas generaciones de indios a las que no les costó asimilar el catolicismo como su religión e incorporar las costumbres europeas con relativa facilidad.

En Extremo Oriente, tanto en China como en Japón, fue totalmente distinto, se impuso una verticalidad en las misiones, es decir, convertir de arriba a abajo. El éxito en la evangelización de los pueblos pasaba primero por un largo proceso de aculturación de los jesuitas, y después, por ganarse a las élites para la causa cristiana (Míguez, 2014, p. 93). Los misioneros jesuitas debían contar con la aprobación de las autoridades locales para poder evangelizar en sus territorios, pero antes debían aparentar ser monjes de una nueva «escuela» religiosa sin tratar de imponer su cultura, y sin llamar la atención como extranjeros, acomodándose a las costumbres, vestimenta y comida de estos lugares (Jiménez Pablo, 2018, pp. 170-171).

En el caso de China, los jesuitas supieron asumir los valores de la sociedad, teniendo especial cuidado con no contradecir sus creencias cristianas. Tuvieron que adaptarse a las reglas y rituales de convivencia social. Los primeros años estudiaron la lengua, aprendieron los hábitos ceremoniales y sociales, y reformularon sus gestos y palabras para no ser expulsados. Entre otras estrategias me gustaría destacar dos que fueron fundamentales para ganarse la credibilidad y confianza de las autoridades: por un lado, su 
apariencia física, el cambio de traje, sus modales, sus movimientos, su muestra de respeto, su distanciamiento, y por el otro, su talante intelectual, es decir, debían mostrarse como sabios maestros no sólo en cuestiones de religión, de las que debían discutir con muchísima precaución, sino mostrar sus conocimientos científicos en el dominio de las matemáticas o de la astronomía. Vestir al modo de los monjes, les permitió una integración más rápida; esta vestimenta era parecida a una sotana, de mangas más amplias, no tan diferente a la jesuita. A lo largo del tiempo llegaron a vestir distintos tipos de túnicas como las de los bonzos budistas, pareciendo una nueva corriente del budismo, para acabar vistiendo el traje de los letrados confucianos. El hecho de vestir como filósofos confucianos les permitía acercarse a las élites pues era la doctrina que éstas practicaban (Peixoto de Araújo, 2000, pp. 89-91).

Como a experiencia he a que melhor ensina, a cabo de dez annos da China, acharão os Padres que convinha vestirem-se de Letrados, criar cabello e barba, acomodarse nas cortesias políticas, nas visitas, nos presentes, porque desta sorte perderiam o infame nome de Bonzos e ganharião o de Letrados, que para a conversam era so o camino mais patente e acertado (Cita Peixoto de Araújo, p. 92).

Lo interesante es la capacidad de los misioneros jesuitas para ir cambiando conforme su aculturación va siendo más efectiva, aunque sea en estos pequeños detalles de vestimenta que resultaban fundamentales para su integración y poder llevar a cabo el apostolado. Ciertamente, los jesuitas en China se sintieron más cómodos dialogando con el Confucionismo por ser considerada como una doctrina filosófica o como una sabiduría con códigos morales que, al conocerlos, les permitía integrarse en la ritualidad de la corte imperial. Por otra parte, muchos de esos códigos no chocaban con el cristianismo. El P. Matteo Ricci, apodado Li Madou no sólo fue considerado como un intelectual respetado por los letrados confucianos, sino que era tratado como uno más de ellos, que además aportaba algo nuevo: hacía de puente entre el conocimiento filosófico, científico, tecnológico y religioso de Occidente con Oriente (Ross, 1994, p. 143). El caso japonés es parecido a lo que ocurrió en China. Para ganarse a la nobleza terrateniente, los daimyos, se vistieron parecidos a los mojes budistas Zen, que tenían relación con estos dirigentes. Los jesuitas discutían con los monjes Zen sobre principios budistas, y cuando ya tenían más confianza, empezaban a introducir en su diálogo los conceptos cristianos (López-Gay, 2000, p. 113). No obstante, el éxito de la Compañía de Jesús en Japón, además de ser su capacidad de adaptación, fue su papel de traductores e intermediarios entre los daimyos y los comerciantes portugueses (Gómez Díez, 2007). No es de extrañar que la actividad de los jesuitas se desarrollara en el sur, donde atracaban las nau do trato. 


\section{LA EDUCACIÓN EN LAS MISIONES Y SUS AGENTES DEL CAMBIO}

«Agentes del cambio» es como el P. Revuelta denominó a los niños nativos que fueron los que realmente asimilaron la evangelización y permitieron la progresiva filtración de la cultura española en algunas comunidades, por medio de la labor pedagógica de la Compañía de Jesús. Además de los niños que integraron lo externo como propio, añadiré otra categoría social que considero agente del cambio igualmente. Se trata de los ayudantes o auxiliares nativos de los jesuitas, que por la escasez de misioneros se convirtieron en un pilar clave para la expansión, adaptación y conservación del cristianismo en los nuevos territorios.

Para los jesuitas, la misión y la educación son dos componentes inseparables; dos caras de la misma moneda. La educación jesuita en las misiones, tanto en América como en Asia, buscaba adaptarse al público al que se dirigía. Es preciso recordar las instrucciones que a este respecto daba el general Francisco de Borja al primer provincial de las Indias Occidentales, el P. Jerónimo Ruiz de Portillo:

Tengan mucha advertencia qué gente es aquella en que han de aprovechar: qué errores y sectas de gentilidad siguen; qué inclinaciones y vicios tiene; si ay doctos o personas de crédito entre ellos, para que estos se procuren ganar, como cabezas de los otros; y qué remedios conformes a estas cosas se les puedan y devan aplicar; y , con los de más entendimiento, procure antes con suavidad de palabras y exemplo de vida afficionarlos al verdadero camino, que por otros rigores. (MHSI MonPer 1, pp. 122-123. Instrucción a Portillo. Marzo 1567)

En el caso de América, los primeros misioneros jesuitas simplificaron mucho el aprendizaje de la doctrina cristiana, al igual que otras órdenes religiosas. Conceptos como la santísima trinidad, la pasión y muerte de Jesús, la resurrección, el Santísimo Sacramento, la gracia divina, eran muy complejos de entender por las comunidades indígenas. Como solución, se recurrió a una catequesis con una metodología muy repetitiva, con frases muy sencillas y cortas que debían ser, más que aprendidas, memorizadas. También recurriendo a bocetos y dibujos en los catecismos. Dosis mínimas, señala Couto (2000, p. 76) que tenían la intención de evitar que surgieran dudas, reparos o contradicciones en el camino del aprendizaje. Probablemente una de las cuestiones más complejas de explicar fue la crucifixión de Cristo; el sacrificio, pues se había tachado de inmoral el ritual del sacrificio humano en las ceremonias de los nativos. Resultaba contradictorio prohibir este rito cuando en el cristianismo el sacrificio es el pilar central sobre el que se sustenta la salvación humana. Era fundamental la suavidad con la que se 
enseñaron estos temas tan delicados, destacando, por ejemplo, el recurso de los misioneros a las cruces atriales que no muestran la figura de cristo crucificado, sino simplemente se representa la cruz con los símbolos de la pasión de Cristo. Estas cruces atriales solían formar parte de la arquitectura de las reducciones jesuitas, situándose en la plaza central de estas «ciudades de indígenas» (Rey Fajardo, 2007, p. 550).

Tal y como lo explica el P. Revuelta en sus artículos, con los niños, una de las estrategias de atracción era la música. Los misioneros se percataron de su importancia en las religiones de las comunidades indígenas. El canto y el juego de sonidos imitando la naturaleza eran parte fundamental del sistema religioso-chamánico de las sociedades amerindias, y los jesuitas lo supieron utilizar a su favor instruyendo a coros de niños indígenas. Como elemento principal en las ceremonias religiosas y en las tareas pastorales se utilizó mucha música cantada, también acompañada de instrumentos como flautas o tambores, consiguiendo una mezcla cultural con identidad propia en las misiones americanas. Hay constancia de cómo los jesuitas se introducían en una nueva comunidad indígena acompañados de un pequeño coro de niños de otros poblados ya cristianizados, que cantaban himnos litúrgicos como carta de presentación de los misioneros (Revuelta, 2007, p. 53; Couto, 2000, p. 73).

Desde que la Compañía de Jesús pisó América, tuvo en mente la fundación de colegios, dirigidos a distintos niños. Por un lado, los dirigidos a la educación de niños nativos, donde se les enseñaba a leer y escribir, así como las creencias, ritos y valores católicos. No podemos perder de vista la educación de los hijos de los colonos. Los jesuitas tenían que atender también las necesidades espirituales de las autoridades, que luego podrían promocionar la fundación de nuevos colegios. Y un tercer tipo que se planteó eran los colegios de hijos de caciques. El conseguir instruir a los hijos de los dirigentes indígenas, era una garantía de conservación y expansión del cristianismo en las misiones. En la Congregación Provincial del Perú, en 1577, se solicitó la fundación de colegios para los hijos de los caciques que servirían de modelo para el resto de los niños (Borja de Medina, 2000, p. 194).

La educación en las misiones del nuevo continente permitió ir, poco a poco, incorporando nativos al trabajo de los misioneros jesuitas. Se trataba de indígenas convertidos que ayudaron a los jesuitas en sus distintas labores y, sobre todo, siendo sus intérpretes. Los misioneros ya debían traer aprendida la lengua de la región a evangelizar. Desde los colegios y universidades aprendían no sólo la metodología misionera, sino la lengua y la cultura con la que iban a tratar. Los largos meses de espera en Sevilla o Lisboa para que les facilitaran la licencia para embarcarse hacia América, no eran tiempos 
muertos, sino de estudio y aprendizaje, especialmente de las lenguas. Con todo, llegaban a los destinos de misiones y las lenguas de las comunidades indígenas eran distintas unas de otras y, en ocasiones, lo que habían aprendido distaba mucho de lo que realmente se hablaba. Así, se hizo vital para el éxito de las misiones que los jesuitas se ayudaran de intérpretes nativos que se hicieron sus auxiliares en la labor apostólica. La implicación de estos nativos fue en aumento y su papel se fue, en cierto sentido, "profesionalizando». Existió una figura, que se dio en algunas misiones, que se conoce como el «fiscal», que era un indio ayudante de los misioneros, nombrado por ellos para supervisar la misión en una comunidad. Había un fiscal por cada capilla levantada, que además estaba al cuidado de la misma. Era enseñado por los misioneros para, en ausencia de ellos, llevar las laboras de la catequesis diaria, como por ejemplo rezar las oraciones con los niños, celebrar procesiones, controlar que los indios se confesaran, o avisar a los sacerdotes de los indios enfermos, fallecidos, recién nacidos. Llegó incluso a ser un nombramiento oficial que recaía en nativos de cierta autoridad y edad (Urbina Carrasco, 2009, p. 115).

En el caso de la educación en las misiones de Asia, encontramos muchas similitudes con la pedagogía aplicada en América, pero también fuertes diferencias. Un claro paralelo es la adecuación del mensaje a enseñar al nativo que lo recibe. En Japón, Valignano era partidario de acomodar el Evangelio y «depurarlo de excrecencias europeas y transportarlas en esencia a la cultura japonesa»(Gómez Díez, 2007, p. 374). También se dio un sincretismo religioso al contacto de las dos culturas, como pasó en América, y que podemos comprobar en las tallas e imágenes de temas católicos con rasgos orientalizantes aplicados a la figura de Cristo, la Virgen o algún santo. Sin embargo, prestaré más atención a las diferencias, que siempre tienen que ver con el nivel de aculturación de nativos o de jesuitas. Un aspecto menos tratado es la edificación de colegios, seminarios e iglesias jesuitas en Asia. En los inicios de las misiones en Japón o China, y en aquellos momentos de persecución a los cristianos, los jesuitas utilizaron pequeños oratorios en casas particulares en la clandestinidad, o construyendo improvisadas habitaciones de madera que podían abandonarse rápidamente sin dejar rastro de su existencia. Después, conforme la situación se iba haciendo más favorable para sus misiones, les fueron regaladas algunas casas, y en aquellos lugares donde el progreso fue mayor, se les permitió reutilizar espacios de culto como algunos templos budistas. Esto obligó a una aclimatación de la Compañía a unos espacios planteados para el culto de otras religiones. Con el tiempo, habiéndose ganado el favor de las autoridades, a partir de 1580 en el caso japonés, y de 1610 en el chino, se llegaron a construir nuevos edificios destinados a la educación 
jesuita, pero siempre integrados en el concepto arquitectónico oriental. Y en estos casos se documenta una síntesis del concepto estético oriental con la funcionalidad del modelo de arquitectura jesuítica. Por ejemplo, en el caso de Japón, la edificación de colegios y seminarios jesuitas, que estuvo muy sujeta al interés comercial de los daimyos con los portugueses, obligó a levantar edificios de hasta tres alturas, siempre integrados en la naturaleza, que además de albergar las estancias propias de todo colegio jesuita: aulas, capillas, biblioteca, etc., contaban también con cuartos para la ceremonia del té, suelos de tatami y espacios para recibir invitados (Jiménez Pablo, 2018, p. 171). De manera que estos cuartos de invitados y las salas de té reflejan el fuerte componente diplomático de estos colegios y seminarios jesuitas, además del educativo, donde mantener un continuo contacto con las élites niponas (Diniz, 2001, p. 114). En ningún caso, podían hacer ostentación de su religión de forma pública, de modo que las fachadas no debían llamar la atención. Las iglesias cristianas, por ejemplo, solían tener una única nave de planta cuadrada o rectangular, no pudiendo realizarlas en forma de cruz latina con varias naves, ya que conllevaba una traslación del modelo occidental a oriente, lo que provocaría cierto rechazo de las poblaciones a un modelo totalmente distinto a los templos de oración típicos del budismo u otras creencias orientales, a los que estaban acostumbrados. Es preciso recordar, que los jesuitas en Asia buscaban la confianza de las élites para que se les permitiera extender el Evangelio, y una vez ganada, debían crear estrategias para conseguir llegar a las poblaciones. Y en este sentido, la adaptación de la arquitectura jesuita es un recurso más para atraer a las gentes del lugar, pues la apariencia del templo, en su forma artística y estética, les resultaba familiar, aunque para ello la Compañía tuviera que alejarse mucho del modelo romano del Gesù o del colegio Imperial de Madrid (Luengo, 2012, pp. 528-538). Sirvió, por tanto, la arquitectura jesuita como proyección de un modelo de espacio cristiano, introduciendo algunos elementos europeos que no desentonasen en la otra cultura. Por último, cabe señalar que sobre esta adaptación de los centros escolares y las iglesias al modelo oriental existen pocos datos que dieran los jesuitas en sus cartas a los superiores italianos o portugueses, dado que no se veía con buenos ojos desde la curia jesuítica una aculturación tan profunda que pudiese restar importancia al mensaje transmitido, o llegase a confundirlo.

En cuanto a los "agentes del cambio» en Oriente pasaba algo parecido a América con respecto a los ayudantes o colaboradores. El siglo XVI fue un siglo de expansión misionera de la Compañía de Jesús, pero a través de pequeñas comunidades cristianas que, a menudo, se encontraban muy dispersas. El número de jesuitas para atenderlas era escaso, de manera que 
visitaban temporalmente dichas comunidades para seguir bautizando, confesando, oficiar misa, etc. En China, los jesuitas se apoyaron en la creación de agrupaciones de laicos (al modo de las confraternidades), más o menos secretas, que ayudaban a rectificar errores de conducta no cristiana, llevaban obras de misericordia, etc. Dentro de esas agrupaciones laicas se elegían a los mejores que se hacían catequistas tras un examen basado en un discurso público (Gatta, 1998, pp. 108-109). Algunos de estos catequistas, a menudo del ambiente de los letrados confucionistas, llegaron a profesar en la Compañía. De nuevo, las misiones en las comunidades contaban con estos nativos que mantenían el fervor cristiano y realizaban las principales tareas de apostolado (Peixoto de Araújo, 2000, p. 96). Estos colaboradores o ayudantes chinos gozaban de autoridad en sus comunidades y de una libertad de movimiento por todo el Imperio que no tenían los jesuitas.

El caso de Japón está mejor documentado. Se adoptó una figura de acólitos o mozos de los monasterios Zen: los dōyokus. Los jesuitas quisieron contar con esta figura en sus colegios, y fueron un gran motor para la expansión y conservación del cristianismo. El valor de los dōyokus se puede medir en sus cifras: en 1580, la misión contaba con 100 doyokus, en 1603 había 280 dōyokus que asistían a unos 140 misioneros, y en 1609 unos 300 dōyokus que asistían a unos 150 misioneros. Al igual que sucedía con esta figura en los templos budistas, ser doyoku era un estado de vida, llevaban la cabeza rapada, y hacían dos promesas; el celibato y la predicación, que también se hacía en la corriente Zen. Asimismo, se formaban en los colegios de la Compañía y, muchos de ellos, se preparaban para su ingreso en la Orden. Entre sus labores, además de su compromiso con el apostolado jesuita, destaca la de intérpretes y encargados de adaptar los catecismos (Ruiz de Medina, 2001, p. 1133). Otra labor importante era la enseñanza de la lengua y literatura japonesa en los seminarios y colegios. Lo normal es que se asignaran doyokus a los misioneros, que les debían tutorizar, intentando que a lo largo de su formación no cambiaran de misionero. Desde la curia jesuítica, al P. Claudio Aquaviva no le gustaba estas asignaciones que podían interpretarse a los dōyokus en Europa como servidores de los jesuitas (Marino, 2015, pp. 145-146). También existió otra figura, la de los kanbōs, que se diferenciaban de los doyokus en que eran como sacristanes y suplentes laicos del misionero en los cuidados pastorales de las comunidades cristianas, y en que no estaban obligados al celibato. Cuidaban de las capillas e iglesias, visitaban enfermos, llevaban las congregaciones cristianas, etc. Desde luego, los kanbō eran menos numerosos que los dōyokus; se documenta para el año 1609 unos 190 kanbōs, uno por congregación. Cabe resaltar la importancia de dōyokus y kanbōs en momento de persecución o de expulsión de la Compañía, como 
ocurrió en 1614, porque ellos continuaron en la clandestinidad con la labor. Y desde luego, muchos de ellos se sumaron a las listas de mártires del Japón (Ruiz de Medina, 2001, p. 1134).

\section{CONCLUSIONES}

El P. Revuelta siempre nos hizo reflexionar sobre la Historia de la Compañía. Su pensamiento historicista le llevó a plantearse qué parte de las reducciones fueron positivas, y qué parte negativas; a lo que se aspiró y lo que realmente se consiguió. En este artículo se han estudiado algunos aspectos de las misiones y educación jesuita que él trataba, relacionados con la aculturación, añadiendo una comparativa con lo sucedido en Asia.

Se ha comenzado por analizar el contexto político en el que se enmarcaron las misiones, tan distinto en una u otra parte del mundo. Tanto fue así, que determinó que la evangelización en América fuera un avance más continuo, frente a la oscilación que se vivió en Asia, a merced de los intereses de las autoridades locales. La conquista de América allanó la entrada de los misioneros a los nuevos territorios, quienes sentían el respaldo de una poderosa corona que desde tiempos de Isabel la Católica tenía el privilegio (por bula papal Inter Caetera, 1493) de dirigir la evangelización en América. De manera que, si los jesuitas querían extender el cristianismo por el nuevo mundo, debían contar con el beneplácito de la corona, que les permitía embarcar a los navíos. El foco en las misiones amerindias, por tanto, hay que colocarlo no sólo en ultramar, sino en el lugar de origen, en las decisiones tomadas desde la corte de Madrid. El caso de Asia es totalmente distinto, partiendo de la base de que las misiones dependían de las relaciones comerciales con la Monarquía portuguesa. Por otra parte, una vez en Oriente, los jesuitas extendían su apostolado si las autoridades locales permitían la predicación en sus territorios. Y esto no siempre se daba; las persecuciones, el martirio y las expulsiones de los jesuitas fueron actos que se sucedieron en territorios asiáticos como Japón, y con ese miedo, cuidado y precaución, tuvieron que trabajar los jesuitas.

El nivel de aculturación se puede analizar en los nativos, pero también en los misioneros. Aculturación de ida y vuelta con diferencias según la región de cada continente y, más aún, según la comunidad de nativos con la que convivieron los jesuitas. Ahora bien, es evidente una mayor aculturación de los misioneros jesuitas en Asia, porque si no hubiesen formado parte de la 
cultura del «otro», si no hubiesen pasado desapercibidos, no se habrían dado las misiones.

Lo que sucedió en la práctica de la actividad apostólica se alejó en muchas ocasiones de las órdenes emitidas desde la curia papal o jesuítica; aunque desde Roma se intentaba dar una uniformidad en la metodología de las misiones, no fue posible aplicarla por circunstancias externas a los jesuitas.

Por último, recordando al P. Revuelta, se han tratado los «agentes del cambio»que favorecieron la actividad de los jesuitas. De cómo los niños en América asimilaron mejor la nueva religión y aprendieron técnicas y costumbres llevadas por los misioneros, originándose un sincretismo cultural, que todavía hoy se mantiene en muchas prácticas. Otros agentes del cambio fueron los auxiliares o colaboradores nativos que se implicaron en la labor pastoral de las misiones y que, en momentos de ausencia de los jesuitas, o en momentos complicados de persecuciones, tuvieron un papel protagonista en la pervivencia de la misión.

\section{REFERENCIAS}

Álvarez-Taladriz, J. L. (1978). Opinión de un Teólogo de la Compañía de Jesús sobre la intervención del poder temporal en la defensa de la labor evangélica en Japón (1599). Sapientia, 12, pp. 173-209.

Batista, J. (1993). Los jesuitas y las lenguas indígenas en La Compañía de Jesús en América: evangelización y justicia. Siglos XVII y XVIII, en Actas del Congreso Internacional de Historia. Córdoba, pp. 11-21.

Borja de Medina, F. (2000). Enseñanza y métodos misionales en América española y Filipinas, en A Companhia de Jesus e a missionação no Oriente. Actas do Colóquio Internacional. Lisboa: Brotéria-Fundação Oriente, pp. 175-200.

Cervera Jiménez, J. A. (2013). Los planes españoles para conquistar China a través de Nueva España y Centroamérica en el siglo XVI. Cuadernos Inter.c.a.mbio, Año 10, Vol. 10, No. 12, pp. 207-234.

Couto, J. (2000). Estratégias e métodos de missionação dos jesuitas no Brasil, en $A$ Companhia de Jesus e a missionação no Oriente. Actas do Colóquio Internacional. Lisboa: Brotéria-Fundação Oriente, pp. 65-84.

Diniz, S. (2001). Jesuit buildings in China and Japan: a comparative Study. BPJS, 3, pp. 107-128.

Gatta, S. (1998). Il natural lume de Cinesi. Teoria e prassi dell' evangelizzazione in Cina nella Breve relatione di Philippe Couplet S. J. (1623-1693). Monumenta Serica Monograph Series 37. Nettetal: Institut Monumenta Serica - Sankt Augustin.

Gómez Díez, J. F. (2007). Unidad y variedad en la misión jesuítica del siglo XVI: del Japón a las fronteras de la monarquía hispánica. Estudios eclesiásticos, 321, pp. 359-387. 
Iparraguirre, I. y Dalmases, C. (eds) (1977). San Ignacio de Loyola, Obras Completas. Madrid, BAC.

Jiménez Pablo, E. (2018). La huella educativa y cultural de los jesuitas en Japón, Miscelánea Comillas. Revista de Ciencias Humanas y Sociales, 76/148, pp. 167-178.

López-Gay, J. (1966). El Catecumenado en la misión del Japón del siglo XVI. Roma: Pontificia Univ. Gregoriana.

López-Gay, J. (1967). Censuras de Pedro de la Cruz S.J., Teólogo del Japón, a las Doctrinas de Francisco Suárez, año 1590. Archivo Teológico Granadino, 30, pp. 213-244.

Luengo Gutiérrez, P. (2012). Arquitectura jesuita en Filipinas y China, en La arquitectura jesuítica: Actas del Simposio Internacional, M. I. Álvaro Zamora, J. Ibáñez Fernández, J. Fermín Criado Mainar (coords.). Zaragoza: Institución Fernando el Católico, pp. 523-540.

Marino, G. (2015). Las Lembranças para Japón: Otro escrito inédito del jesuita Gil de la Mata, Acta Literaria, 51, pp. 135-159.

Martínez Millán, J. (2003). La crisis del "partido castellano» y la transformación de la Monarquía Hispana en el cambio de reinado de Felipe II a Felipe III. Cuadernos de Historia Moderna. Anejos, 2, pp. 11-38.

Martínez Millán, J. y Fernández Conti, S. (2005). La monarquía de Felipe II: la Casa del Rey. Madrid: Fundación MAPFRE Tavera.

Míguez Santa Cruz, A. (2014). Referencias histórico-culturales en los escritos de los Jesuitas en el Japón del siglo XVI. Hispania Sacra, 66/133, pp. 75-107.

Morales, M. Ma (1995). Los comienzos de las Reducciones de la Provincia del Paraguay en la relación con el Derecho Indiano y el Instituto de la Compañía de Jesús. Evolución y conflictos. Roma: Universidad Gregoriana.

Monumenta Historica Societatis Iesu, Monumenta Peruana, vol. 1, Roma, 1954.

Peixoto de Araújo, H. (2000). Processo de aculturação e métodos missionários no imperio da China, en A Companhia de Jesus e a missionação no Oriente. Actas do Colóquio Internacional. Lisboa: Brotéria-Fundação Oriente, pp. 85-102.

Rey Fajardo, José del (2007). Los jesuitas en Venezuela. Las misiones germen de la nacionalidad. Caracas-Bogotá: Universidad Católica Andrés Bello-Pontificia Universidad Javeriana.

Revuelta González, M. (1988). Las misiones de los jesuitas españoles en América y Filipinas durante el siglo XIX. Miscelánea Comillas. Revista de Ciencias Humanas y Sociales, 46/88-89, pp. 339-390.

Revuelta González, M. (1988). Los colegios jesuitas en Hispanoamérica en el siglo XIX, en Historia de las relaciones educativas entre España y América: actas del Coloquio Nacional de Historia de la Educación. Sevilla, pp. 441-447.

Revuelta González, M. (1994). La educación en América y Filipinas: enseñanza de los jesuitas en Hispanoamérica, en Historia de la Educación en España y América, B. Delgado Criado (coord.), vol. 3, Madrid: Fundación Santa María, pp. 235-239.

Revuelta González, M. (1996). Los ritos chinos y los jesuitas en el siglo XVIII, según la documentación franciscana. Miscelánea Comillas. Revista de Ciencias Humanas y Sociales, 54/104, pp. 143-173.

Revuelta González, M. (2007). Jesuitas en América: utopía y realidad en las reducciones del Paraguay, en Jesuitas: una misión, un proyecto, J. I. Tellechea Idígoras (coord.). Bilbao: Universidad de Deusto, pp. 31-57. 
Ross, A. C. (1994). A Vision Betrayed. The Jesuits in Japan and China 1542-1742. Edinburgh: Edinburgh University Press.

Ruiz de Medina, J. (2000). Métodos misionales para la evangelización de Corea, en $A$ Companhia de Jesus e a missionação no Oriente. Actas do Colóquio Internacional. Lisboa: Brotéria-Fundação Oriente: pp. 133-160.

Ruiz de Medina, J. (2001). "dōyokus», en Diccionario histórico de la Compañía de Jesús, Tomo II, Charles E. O’Neill y J. M. Domínguez (dirs.). Roma-Madrid: IHSI, UPCo, p. 1133.

Urbina Carrasco, M. X. (2009). La frontera de arriba en Chile colonial: interacción hispano-indígena en el territorio entre Valdivia y Chiloé e imaginario de sus bordes geográficos, 1600-1800. Valparaíso: Ediciones Universitarias de Valparaíso. 